\title{
Rat adult stem cell differentiation into immature retinal cells
}

\author{
Ma Teresa González-Garza*, Jorge E. Moreno-Cuevas
}

Servicio de Terapia Celular, School of Medicine, Tecnológico de Monterrey, Monterrey, México;

*Corresponding Author: mtgonzalezgarza@itesm.mx

Received 4 February 2012; revised 10 March 2012; accepted 5 April 2012

\begin{abstract}
Cell therapy has been proposed as an alternative treatment for retinal diseases. Applications involving stem cells have shown that undifferentiated cells fail to engraft and cannot convert to retinal cells. However, positive results have been reported for retinal precursor cells, suggesting that this approach is the best option. Unfortunately, the source of this cell type is controversial. Predifferentiated adult stem cells may provide an alternative source of cells. The present study proposes a sequential culture media aimed at inducing cells from this source into a preretinal-like lineage. Rat bone marrow stem cells were cultivated in a neuroinduction mix medium for $24 \mathrm{~h}$. The sequence involves immunocytochemistry to detect nestin and tubulin III to demonstrate the cell's neuronal lineage, followed by incubation in retinal-induction mixed medium for $\mathbf{2 4} \mathrm{h}$. RT-PCR was performed to detect expression of Brn3b, Pax6, THY1.1, Opn4, and Ath5 genes. Immunocytochemistry results showed increased expression of nestin and tubulin III after $24 \mathrm{~h}$ of incubation in the neuroinduction medium. RT-PCR showed slightly increased expression of Pax6, THY1.1, and Opn4 after $48 \mathrm{~h}$ of sequential incubation in the neuroinduction and predifferentiation media. Brn3b and Ath5 gene expression increased markedly. These results suggest that mesenchymal stem cells have a high predisposition to differentiate into preretinal-like cells with minimal time in culture. These cells may provide a viable alternative for restoring damaged retinas.
\end{abstract}

Keywords: Cell Therapy; MSC; Regenerative Medicine; Retinal Diseases; Stem Cells

\section{INTRODUCTION}

Retinal diseases represent a major source of visual disability worldwide. Glaucoma, the most common cause of retinal injury, is caused by metabolic or genetic diseases [1]. In this condition, ganglion cells are lost as part of the optic nerve degeneration [2]. At present, there are no therapeutic options for functional recovery of the nerve because it is derived from the retinal cell axon $[3,4]$. Cell therapy is a potential alternative for restoring damaged cells in neurodegenerative diseases [5], including retinopathies. It has been suggested that recovery of ganglion cells and their grown axons might be feasible and, if so, might restore the optic nerve [6-8]. With this target in mind, several groups have focused on the possible engraftment of differentiated or undifferentiated embryonic stem cells (ESCs) into animal models of damaged retinas. The results show that retinal cells derived from human and animal ESCs migrate and engraft into damaged retinas, where the cells differentiate into functional photoreceptors and restore light responses in animals [9-16]. Although ESCs have been suggested as possible repositories of retinal cells, the feasibility of applying these techniques to human clinical protocols are distant because of the ethical and immunological implications.

Current methods of somatic cell reprogramming have developed protocols for generating retinal cell types. These studies have shown that induced pluripotent stem cells (iPSCs) from human fibroblasts can differentiate into retinal progenitor cells $[17,18]$. Even though these results are promising, these progenitor cells are still slow and inefficient, and some doubts have emerged about their altered genetics and limited viability [18-21].

Adult undifferentiated or differentiated stem cells have also been used for retinal replacement. Among them, Schwann cells have been transplanted intravitreally into an optic nerve transaction model, and the results showed promising retinal ganglion cell (RGC) survival [22]. Adult hippocampal neural progenitor cells also show engraftment, survival capability, and morphological transformation reminiscent of retinal neurons and an extension of processes into the optic nerve [23-26]. Retinal pigment epithelium cells (RPECs) can engraft into and 
survive in Bruch's membrane [27-32], although in clinical trials in patients with advanced age-related macular degeneration, allogenically transplanted human RPECs have a high rejection rate [33].

Adult stem cell transplantation using cells obtained from the blood or bone marrow and predifferentiated in culture is another promising alternative for retinal regeneration in humans. Preclinical studies with bone marrow cells transplanted into the retina have shown that the inoculated cells produce a high rate of neovascularization, engraft and possibly differentiate into cells of neuronal lineage, and delay retinal degeneration [34-37]. Although one study reported that a degenerated retina cannot itself provide the signals to induce the differentiation of retinal stem cells (RSCs) into photoreceptors [38], the best results were obtained when predifferentiated cells were transplanted; the results were even better than were those with completely differentiated cells [39]. Studies of transplanted retinal precursor cells (RPC) have suggested that the predifferentiation of RSCs is the best option for recovery of a damage retina $[38,40]$.

Several mixed media have been suggested to induce adult stem cell differentiation into neuronal lineage cells or ganglion cells. The formulas of those media include growth factors and chemical compounds involved in neuronal lineage and ganglion differentiation [41-43]. The present study focused on the development of a sequential culture medium aimed at inducing adult stem cells to differentiate into immature neuronal cells and then into immature retinal cells in a minimal time, that would provide an option for the treatment of retinal disease.

\section{MATERIALS AND METHODS}

\subsection{Mesenchymal Cell Isolation and Culture}

Mesenchymal stem cells (MSCs) were obtained from adult Wistar male rats, weighing about $220 \mathrm{~g}$. The femurs were washed with Hank's solution to extrude the marrow from the central canal (Gibco, Grand Island, NY, USA) and filtered through a $70 \mu \mathrm{m}$ cell strainer (BD Falcon, Bedford, MA, USA). After centrifugation, cells were resuspended in Dulbecco's modified Eagle medium (DMEMF12) containing 20\% fetal bovine serum (FBS) and 1\% antibiotics (streptomycin-penicillin, Gibco). Cells were seeded in a $100 \mathrm{~mm}$ culture dish (Corning Inc., Corning, NY, USA) at $37^{\circ} \mathrm{C}$ and $5 \% \mathrm{CO}_{2}$ in a humid chamber for $24 \mathrm{~h}$. To remove nonadherent cells, the cells were washed

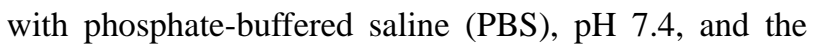
culture medium was replaced with DMEM-F12 containing $10 \%$ FBS and 1\% antibiotics. After 10 days, the cells reached $80 \%$ confluence and were harvested by incubation with $0.25 \%$ trypsin and 1 mM EDTA (Gibco) for 10 min at $37^{\circ} \mathrm{C}$. The obtained cells were split $1: 3$ for the experiments.

\subsection{Predifferentiated Medium and Induction Medium}

For stem cell induction into neuronal lineage cells, the cells were incubated for $24 \mathrm{~h}$ in predifferentiation medium (PM) comprising DMEM-F12 plus $0.1 \mu \mathrm{M}$ retinoic acid, $1 \mathrm{mM} \beta$-mercaptoethanol, $10 \mathrm{ng} / \mathrm{ml}$ fibroblast growth factor 8 (Sigma, St. Louis, MO, USA), and $2 \mathrm{mM}$ glutamine (Invitrogen, Grand Island, NY, USA). To induce retinal lineage cells, a modification of a previously described protocol was used (17). This induction medium (IM) comprised PM plus $10 \mathrm{ng} / \mathrm{ml}$ Insulin Growth Factor -1 (Sigma), 10 ng/ml Dickkopf-1-related protein (Dkk1; R\&D Systems, Minneapolis, MN, USA) and $10 \mathrm{ng} / \mathrm{ml}$ Noggin (GenWay Biotech, Inc., San Diego, CA, USA). Immunocytochemistry and Reverse transcription polymerase chain reaction RT-PCR analysis was performed after $24 \mathrm{~h}$ of incubation in IM.

\subsection{Immunocytochemistry}

Circular glass cover slips treated with poly-l-lysine (Sigma) were placed into 24-well microplates (Corning, Inc.) for immunocytochemistry, and the cells were cultured at a density of $1 \times 10^{5}$ cells/well for $24 \mathrm{~h}$ in PM and then for $24 \mathrm{~h}$ in IM. The cells were fixed with $4 \%$ paraformaldehyde for $10 \mathrm{~min}$; washed three times with PBS, $\mathrm{pH} 7.4$; and then permeabilized with $0.3 \%$ Triton X-100 in PBS for 5 min. Nonspecific antibody reactions were blocked with $5 \%$ bovine sera albumin (BSA) in PBS for $1 \mathrm{~h}$. To confirm the neuronal lineage, cells were incubated overnight at $4^{\circ} \mathrm{C}$ with primary mouse monoclonal antibodies to nestin (1:5000; R\&D Systems) and $\beta$-tubulin III (1:2000; Promega, Madison, WI, USA) diluted in $1 \%$ BSA in PBS. To confirm the ganglion lineage, cells were incubated with monoclonal anti-Pax6 (Santa Cruz Biotechnology, Santa Cruz, CA, USA), anti-Thy (1:400; Abcam [MRC OX-7]), and polyclonal anti-Brn3b (1:50; R\&D Systems [sc-31989]). The cells were washed three times with PBS and incubated with secondary goat antimouse-Fc-fluorescein isothiocyanate (FITC) (Pierce Biotechnology, Thermo Fisher Scientific, Rockford, IL, USA) and donkey anti-goat IgG-FITC (Santa Cruz Biotechnology) for $2 \mathrm{~h}$ in the dark. The nuclei were stained with 4',6-diamidino-2-phenylindole (DAPI, Santa Cruz Biotechnology). The cover slips with stained cells were mounted on slides with $90 \%$ glycerol in PBS and sealed. The cells were analyzed under a fluorescence microscope (Imager Z1 Zeiss, Jena, Germany). Images were taken using an AxioCam HRm camera system coupled to the microscope. 


\subsection{RNA Isolation and RT-PCR}

MSCs were added to poly-l-lysine-treated six-well microplates (Corning Inc.) at a density of $5 \times 10^{5}$ cells/ well and cultured for $2 \mathrm{~h}$ and $24 \mathrm{~h}$. Total RNA was isolated from undifferentiated mesenchymal cells, and from cells incubated in PM and IM using a binding silica column kit (GenElute Mammalian Total RNA, Sigma). The amount and quality of RNA were determined on a GeneQuant Pro Spectrophotometer (Amersham Biosciences, ambridge, UK). RT-PCR was performed in a Px2 Thermal Cycler (Thermo Electron Co, Milford, USA) using one-step reactions (Qiagen, Crawley, UK). All primers were obtained from MWG-Biotech, Huntsville, AL, USA, and are described on Table 1. The RT-PCR reactions were performed in a final volume of $50 \mu \mathrm{l}$ with $1 \mu \mathrm{g}$ of total RNA, according to the Qiagen One-Step RT-PCR protocol. PCR reactions were resolved on $2 \%$ agarose gels. The bands were observed under UV light and photographed in a UVP High-performance UV Transilluminator (DigiDoc-IT, Cambridge, UK) and analyzed with the GelAnalyzer program. Rat retinal tissue from two-month-old adult Wistar male rats was used as the positive control.

\subsection{Statistics}

The statistical differences amongst groups were analyzed using unpaired Student's t-test. Significance was set at a p-value of less than 0.05 . Statistical analyses were performed with SPSS software (v. 17.0; SPSS Inc., Chicago, IL). For each variable under study, medians, standard deviations, and ranges were calculated.

\section{RESULTS}

\subsection{Cell Culture and Predifferentiation}

Primary culture of stem cells recovered from the rat bone marrow showed characteristic Colony forming units
(CFU) formation after 8 days incubation in DMEM-F12 medium (Figure 1(A)). After 12 days, the culture reached $80 \%$ confluence (Figure 1(B)). On passage 4 , the cells were incubated in PM medium for 24 h. Light microscopy showed morphological changes from typical fibroblast-like cells to cells with a triangular body and long projections (Figure 1(C)), which were longer in cells incubated for $24 \mathrm{~h}$ in IM. In the latter incubation, some types of contact, which resembled dendritic contacts, were observed between the cells (Figure 1(D)).

\subsection{Immunocytochemistry}

To probe the possible neuronal lineage, nestin and tubulin III were detected by immunocytochemistry in cells cultured for $24 \mathrm{~h}$ in PM. Slight positive expression of tubulin III was observed around the nucleus in cells cultured in the control medium. The expression of tubulin III increased markedly in cells incubated for $24 \mathrm{~h}$ in PM, and its distribution was detected throughout the cytoplasm (Figures 2(A) and (B)). A similar distribution was observed for nestin in cells cultured in the control medium, and the amount of protein increased in cells cultured in PM. Immunocytochemistry also confirmed the morphological modification of the cells from fibroblast-like cells to cells with a triangular body and long projections (Figures 2(C) and (D)).

To detect the possible predifferentiation to the retinal lineage, after incubation for $24 \mathrm{~h}$ in PM and then for $24 \mathrm{~h}$ in IM, the cells were stained with antibodies to Thy1.1, Pax6, and Brn3b. Thy1.1 immunodetection showed slight staining around the nucleus of the cells incubated in control medium (Figure 3(A)). The staining increased markedly in cells incubated in PM medium for $24 \mathrm{~h}$ follow by $24 \mathrm{~h}$ in IM. These cells also showed modifications of the cell morphology including the presence of long cytoplasmic projections (Figure 3(B)). Immunodetection of Pax6 and Brn3b showed a different distribution. These genes are expressed in the nucleus, therefore we

Table 1. Primers used for RT-PCR gene detection.

\begin{tabular}{ccc}
\hline gene & \multicolumn{1}{c}{ sense } & antisense \\
\hline GAPDH & GTGGGGCAGCCCAGAACATC & CCAGGCGGCATGTCAGATCC \\
Tuj1 & TGGCCACCGTCTTCCGTGGG & TCTCCCCCTCCTCCTCGGCA \\
nestin & CCCCAGGCTGAGGGGATCCAG & GGCATCTCCTACCCCCGGGAC \\
Ath5 & TGCCGCAATGGGGCCAGG & AGCTGGCCATGGGGAAGGAC \\
Brn3b & CACCATCCGCCCCACCACAG & CTCCGAGGAGGGCCTTGGCT \\
Thy 1.1 & CGAGTCTCGGGCCAGAATCCCA & CAGGAGCAGCAGCAGCCAGG \\
Pax6 & TGTCCAACGGATGTGTGAGT & TTTCCCAAGCAAAGATGGAC \\
Opn4 & CCATAGCATTCACGGTGTTG & TTATTTTCCCGTGCCTTGTC \\
\hline
\end{tabular}




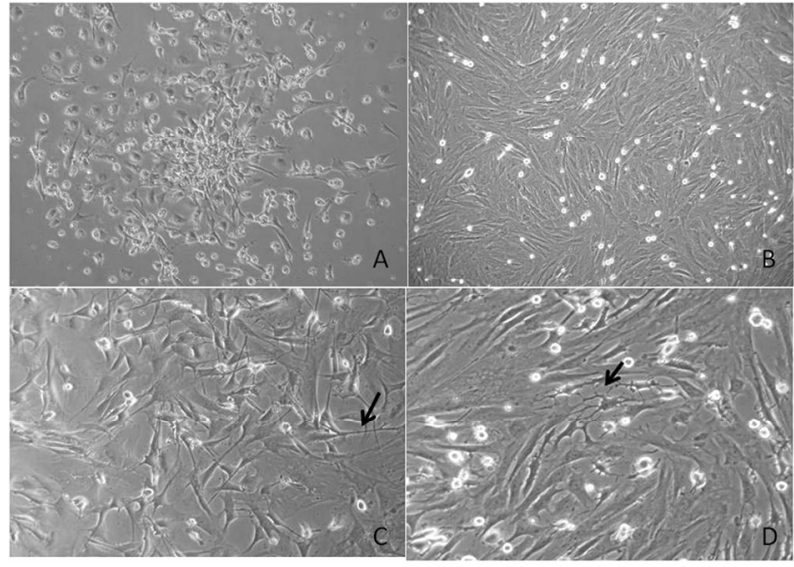

Figure 1. Light microscopy of rat stem cells cultured in control and induction media. (A) Primary culture of stem cells recovered from the rat bone marrow showed characteristic CPU; (B) Confluent culture after 12 days in control medium; (C) Stem cells after $24 \mathrm{~h}$ of culture in PM showing triangular bodies with long projections (arrow); (D) Stem cells after $24 \mathrm{~h}$ of culture in PM plus $24 \mathrm{~h}$ of culture in IM showing cytoplasmic elongation (arrow).

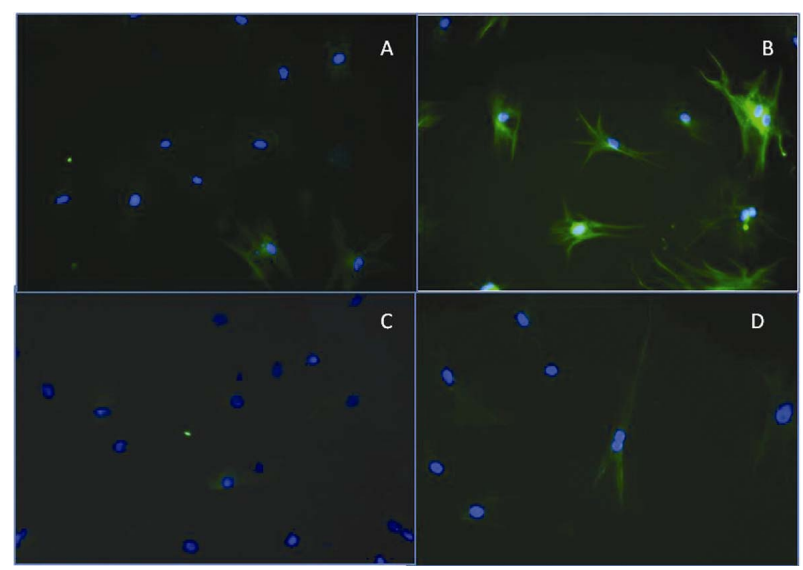

Figure 2. Representative images of immunofluorescent detection of $\beta$-tubulin III and nestin in rat stem cells. (A) Positive staining for $\beta$-tubulin III was detected around the nucleus (green) in stem cells incubated in control medium; (B) After 24 $\mathrm{h}$ of incubation in PM, the distribution was detected throughout the cytoplasm. The nucleus is labeled with 4',6-diamidino-2phenylindole (DAPI) (blue); (C) Representative images of nestin immunodetection in stem cells cultured in control medium show its detection around the nucleus (green); (D) Immunodetection of nestin in stem cells cultured in PM medium for $24 \mathrm{~h}$ showing its distribution throughout the cytoplasm. The nucleus is labeled with DAPI (blue).

did not use DAPI during the immunodetection because nuclear staining could give false information. Immunodetection showed barely detectable staining for these proteins in cells incubated with control medium (Figures 3(C) and (E)).

However, staining increased markedly after incubation for $24 \mathrm{~h}$ in PM plus $24 \mathrm{~h}$ with IM (Figures 3(D) and (F)).

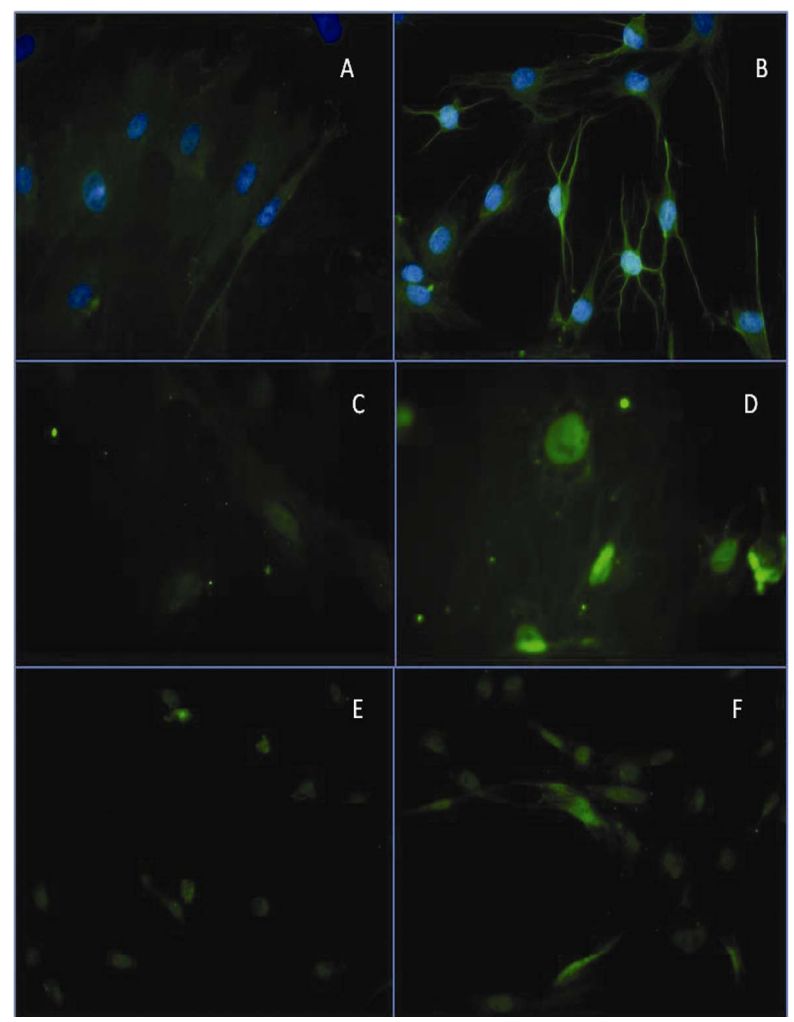

Figure 3. Representative images of Thy1.1 immunodetection. (A) Immunodetection of Thy1.1 in stem cells cultured in control medium; (B) Immunodetection of Thy1.1 in stem cells cultured in PM medium for $24 \mathrm{~h}$ and in IM for $24 \mathrm{~h}$; (C) Immunodetection of Brn3b in stem cells cultured in control medium; (D) Positive immunodetection of Brn3b in stem cells cultured in PM for $24 \mathrm{~h}$ and in IM medium for $24 \mathrm{~h}$; (E) Immunodetection of Pax6 in stem cells cultured in control medium; (F) Immunodetection of Pax6 gen in stem cells cultured in PM for $24 \mathrm{~h}$ and in IM medium for $24 \mathrm{~h}$.

\subsection{RT-PCR}

Pax6, Opn4, Brn3b, Thy1.1, and Ath5 gene transcripttion was detected in stem cells cultured in control medium. The expression levels differed between genes. The expression levels were highest for Pax6, Thy1.1, and Opn4; lower for Brn3b, and marginal for Ath5. After culture of stem cells for $24 \mathrm{~h}$ in PM followed by $24 \mathrm{~h}$ with IM, expression of Brn3b and Ath5 increased by fivefold and threefold, respectively, compared with cells incubated in the control medium. Only minor levels of Pax6, Thy1.1, and Opn4 expression were observed (Figure 4).

\section{DISCUSSION}

The use of adult stem cells to restore retinal cells has been shown to be effective without the need for the cells to go through the path of full differentiation into a retinal cell. There is evidence that cells must be predifferentiated but not differentiated to allow proper retinal integra- 


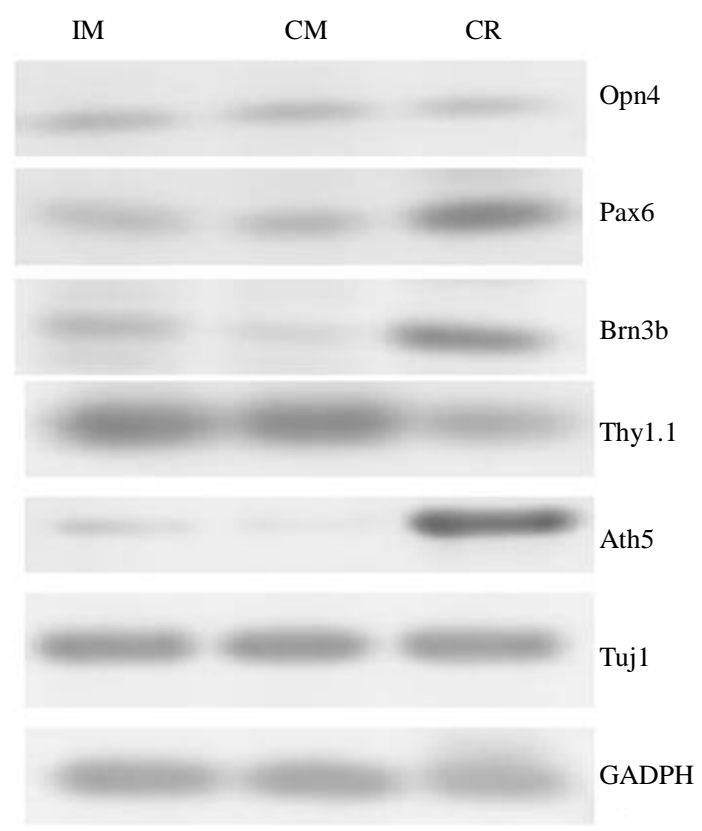

(a)

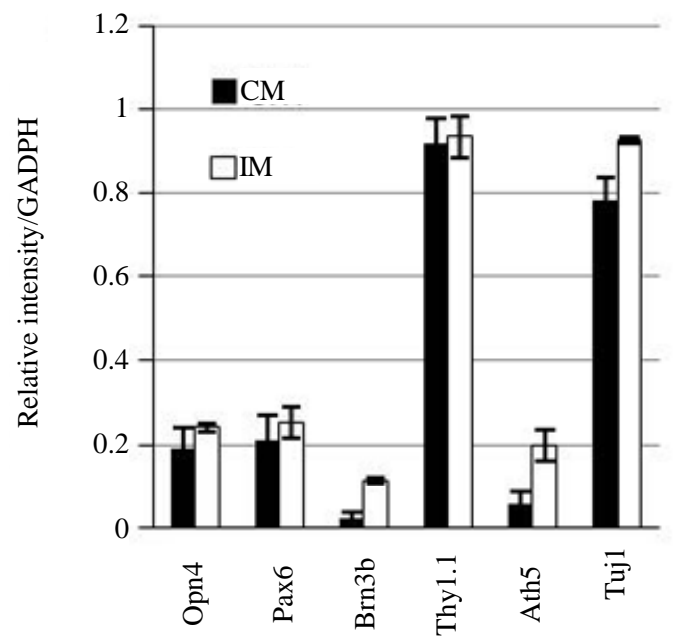

(b)

Figure 4. RT-PCR products for Pax6, Brn3b, Opn4, Thy1.1, and Ath5 in mesenchymal stem cells. (a) Image of the results of gel agarose electrophoresis of RT-PCR products from mRNA from cells cultured in DMEM-F12 medium plus 5\% BSA (CM), or induction medium (IM). mRNA from rat retina was used as the positive control (CR); (b) Graphic representation of the relative intensity of RT-PCR products of cells cultured in CM or IM.

tion [39]. Thus, it is important to design a medium that will obtain predifferentiated retinal cells. In this study, stem cells were cultured in a PM designed to induce predifferentiation to cells of the neuronal lineage. These cells expressed nestin and tubulin III, confirming their predifferentiation into the neuronal lineage. Nestin is a neuroectodermal marker also expressed in RSCs and in most cells in the RGC layer [44,45]. Tubulin III, also a neuronal marker, is present in both immature and mature neurons. After the differentiation into the neuronal lineage was confirmed, the cells were incubated with IM supplemented with Dkk1, Noggin, and IGF-1. Dkk1 promotes stem cell differentiation into a preretinal stage [46-49], Noggin promotes neurogenesis in vitro and inhibits glial cell differentiation [50], and IGF-1 is essential for normal growth and central nervous system development [51]. This combination induces the differentiation of iPSCs and human embryonic cells into derived photoreceptors $[10,17]$.

To support this preretinal linage, the gene expression of Pax6, Brn3b, THY1.1, Opn4, and Ath5 was analyzed. Pax6 plays an important role as a transcription factor in the master regulatory gene needed for the establishment of the retinal field in the forebrain neuroectoderm. This transcription factor is essential for the proliferation and expansion of RSCs in vitro [52,53]. In cultured retinal progenitor cells, Pax6 and Brn3b expression has been confirmed as a positive marker during differentiation [54-56]. Brn3b is a transcription factor for POU proteins involved in differentiation of RGCs and is regulated by Ath5 [57]. More importantly, Brn3b promotes RGC differentiation and suppresses non-RGC differentiation [58]. Ath5 over expression increases RGCs [59-61]. In our system, MSCs expressed all the genes tested at baseline. This observation has been reported for other neuronal genes in MSCs, but apparently these are not functionally [40,62]. However, the overexpression of Brn3b and Ath5 detected in the cells incubated in the sequential media suggest that the cells could become functional RGCs.

This is an important finding because of the pluripotency of RSCs and their ability to differentiate into various retinal cell types, including photoreceptors [40,42].

\section{CONCLUSION}

These findings open the possibility for assessing the potency of these cells and their role in the replacement of cells lost in damaged retinas. These findings also raise the possibility of using autologous transplantation to minimize the risk of immune rejection.

\section{ACKNOWLEDGEMENTS}

This work was funded partially by endowments from Instituto Tecnologico de Estudios Superiores de Monterrey (cat-134) and the Zambrano-Hellion Foundation. The authors express their appreciation to Rosa Maria de la Rosa and Griselda Bautista for technical assistance.

\section{REFERENCES}

[1] Quigley, H.A. and Broman, A.T. (2006) The number of 
people with glaucoma worldwide in 2010 and 2020. British Journal of Ophthalmology, 90, 262-267.

doi:10.1136/bjo.2005.081224

[2] Morgan, J.E. (2000) Optic nerve head structure in glaucoma: Astrocytes as mediators of axonal damage. Eye, 14, 437-444. doi:10.1038/eye.2000.128

[3] Quigley, H.A., Nickells, R.W., Kerrigan, L.A, Pease, ME, Thibault, D.J. and Zack, D.J. (1995) Retinal ganglion cell death in experimental glaucoma and after axotomy occurs by apoptosis. Investigative Ophthalmology and Visual Science, 36, 774-786.

[4] Soto, I., Pease, M.E., Son, J.L., Shi, X., Quigley, H.A. and Marsh-Armstrong, N. (2011) Retinal ganglion cell loss in a rat ocular hypertension model is sectorial and involves early optic nerve axon loss. Investigative Ophthalmology and Visual Science, 52, 434-441. doi:10.1167/iovs.10-5856

[5] Hess, D.C and Borlongan, C.V. (2008) Stem cells and neurological conditions. Cell Proliferation, 41, 94-114. doi:10.1111/j.1365-2184.2008.00486.x

[6] Daley, G.Q. and Scadden, D.T. (2008) Prospects for stem cell-based therapy. Cell, 132, 544-548. doi:10.1016/i.cell.2008.02.009

[7] Enzmann, V., Yolcu, E., Kaplan, H.J, and Ildstad, S.T. (2009) Stem cells as tools in regenerative therapy for retinal degeneration. Archives of Ophthalmology, 127, 563571. doi:10.1001/archophthalmol.2009.65

[8] Ballios, B.G. and van der Kooy, D. (2010) Biology and therapeutic potential of adult retinal stem cells. Canadian Journal of Ophthalmology, 45, 342-351.

[9] Adolph, A.R., Zucker, C.L., Ehinger, B. and Bergström, A. (1994) Function and structure in retinal transplants. Journal of Neural Transplantation and Plasticity, 5, 147-161. doi:10.1155/NP.1994.147

[10] Lamba, D.A., Karl, M.O., Ware, C.B. and Reh, T.A. (2006) Efficient generation of retinal progenitor cells from human embryonic stem cells. Proceedings of the $\mathrm{Na}$ tional Academy of Sciences of USA, 103, 12769-12774. doi:10.1073/pnas.0601990103

[11] Meyer, J.S., Katz, M.L., Maruniak, J.A. and Kirk, M.D. (2006) Embryonic stem cell-derived neural progenitors incorporate into degenerating retina and enhance survival of host photoreceptors. Stem Cells, 24, 274-283. doi:10.1634/stemcells.2005-0059

[12] Banin, E., Obolensky, A., Idelson, M., Hemo, I., Reinhardtz, E., Pijarsky, E., Ben-Hur, T. and Reubinoff, B. (2006) Retinal incorporation and differentiation of neural precursors derived from human embryonic stem cells. Stem Cells, 24, 246-257. doi:10.1634/stemcells.2005-0009

[13] Lamba, D.A., Gust, J. and Reh, T.A. (2009) Transplantation of human embryonic stem cell-derived photoreceptors restores some visual function in $\mathrm{Crx}$-deficient mice. Cell Stem Cell, 4, 73-79. doi:10.1016/j.stem.2008.10.015

[14] Aoki, H., Hara, A., Niwa, M., Yamada, Y. and Kunisada, T. (2009) In vitro and in vivo differentiation of human embryonic stem cells into retina-like organs and comparison with that from mouse pluripotent epiblast stem cells.
Development Dynamics, 238, 2266-2279. doi:10.1002/dvdy.22008

[15] Francis, P.J., Wang, S., Zhang, Y., Brown, A., Hwang, T., McFarland, T.J., Jeffrey, B.G., Lu, B., Wright, L., Appukuttan, B., Wilson, D.J, Stout. J.T., Neuringer, M., Gamm, D.M. and Lund, R.D. (2009) Subretinal transplantation of forebrain progenitor cells in nonhuman primates: Survival and intact retinal function. Investigative Ophthalmology and Visual Science, 50, 3425-3431. doi:10.1167/iovs.08-2908

[16] Wang, S., Girman, S., Lu, B., Bischoff, N., Holmes, T., Shearer, R., Wright, L.S., Svendsen, C.N., Gamm, D.M. and Lund, R.D. (2008) Long-term vision rescue by human neural progenitors in a rat model of photoreceptor degeneration. Investigative Ophthalmology and Visual Science, 49, 3201-3206. doi:10.1167/iovs.08-1831

[17] Lamba, D.A., McUsic, A., Hirata, R.K., Wang, P-R., Russell, D. and Reh, T.A. (2010) Generation, purification and transplantation of photoreceptors derived from human induced pluripotent stem cells. PLoS ONE, 5, e8763. doi:10.1371/journal.pone.0008763

[18] Kokkinaki, M., Sahibzada, N. and Golestaneh, N. (2011) Human induced pluripotent stem-derived retinal pigment epithelium (RPE) cells exhibition transport, membrane potential, polarized VEGF secretion and gene expression pattern similar to native RPE. Stem Cells, 29, 825-835. doi:10.1002/stem.635

[19] Mao, W., Yan, R.T. and Wang, S.Z. (2008) Reprogramming chick RPE progeny cells to differentiate towards retinal neurons by ash1. Molecular Vision, 14, 2309-2320.

[20] Belmonte, J.C., Ellis, J., Hochedlinger, K. and Yamanaka S. (2009) Induced pluripotent stem cells and reprogramming: Seeing the science through the hype. Nature Reviews Genetics, 10, 878-883.

[21] Wang, S.Z., Ma, W., Yan, R.T. and Mao, W. (2010) Generating retinal neurons by reprogramming retinal pigment epithelial cells. Expert Opinion on Biological Therapy, 10, 1227-1239.

[22] Li, S., Hu, B., Tay, D., So, K.F. and Yip, H.K. (2004) Intravitreal transplants of Schwann cells and fibroblasts promote the survival of axotomized retinal ganglion cells in rats. Brain Research, 1029, 56-64. doi:10.1016/j.brainres.2004.09.038

[23] Takahashi, M., Palmer, T.D., Takahashi, J. and Gage, F.H. (1998) Widespread integration and survival of adult-derived neural progenitor cells in the developing optic retina. Molecular and Cellular Neuroscience, 12, 340-348. doi:10.1006/mcne.1998.0721

[24] Nishida, A., Takahashi, M., Tanihara, H., Nakano, I., Takahashi, J.B., Mizoguchi, A., Ide., C. and Honda, Y. (2000) Incorporation and differentiation of hippocampus-derived neural stem cells transplanted in injured adult rat retina. Investigative Ophthalmology and Visual Science, 41, 42684274.

[25] Kurimoto, Y., Shibuki, H., Kaneko, Y., Ichikawa, M., Kurokawa, T., Takahashi, M. and Yoshimura, N. (2001) Transplantation of adult rat hippocampus-derived neural stem cells into retina injured by transient ischemia. Neuroscience Letter, 306, 57-60. 
doi:10.1016/S0304-3940(01)01857-2

[26] Guo, Y., Saloupis, P., Shaw, S.J. and Rickman, D.W. (2003) Engraftment of adult neural progenitor cells transplanted to rat retina injured by transient ischemia. Investigative Ophthalmology and Visual Science, 44, 3194-3201. doi:10.1167/iovs.02-0875

[27] Sheedlo, H.J., Li, L.X. and Turner, J.E. (1989) Functional and structural characteristics of photoreceptor cells rescued in RPE-cell grafted retinas of RCS dystrophic rats. Experimental Eye Research, 48, 841-854. doi:10.1016/0014-4835(89)90067-5

[28] Sauve, Y., Klassen, H., Whiteley, S.J.O. and Lund R.D. (1998) Visual field loss in RCS rats and the effect of RPE cell transplantation. Experimental Neurology, 152, 243250. doi:10.1006/exnr.1998.6849

[29] Klassen, H., Whiteley, S.J.O., Young, M.J. and Lund R.D. (2001) Graft location affects functional rescue following RPE cell transplantation in the RCS rat. Experimental Neurology, 169, 114-121. doi:10.1006/exnr.2000.7617

[30] Gouras, P., Lopez, R., Kjeldbye, H., Sullivan, B. and Brittis, M. (1989) Transplantation of retinal epithelium prevents photoreceptor degeneration in the RCS rat. Progress in Clinical and Biological Research, 314, 659-671.

[31] Phillips, S.J., Sadda, S.R., Tso, M.O., Humayan, M.S., de Juan, E. Jr. and Binder, S. (2003) Autologous transplantation of retinal pigment epithelium after mechanical debridement of Bruch's membrane. Current Eye Research, 26, 81-88.

[32] Hu, Y., Zhang, T., Wu, J., Li, Y., Lu, X., Qian, F., Yin, Z. and Ma, Z. (2008) Autologous transplantation of RPE with partial-thickness choroid after mechanical debridement of Bruch membrane in the rabbit. Investigative Ophthalmology and Visual Science, 49, 3185-3192. doi:10.1167/iovs.07-1299

[33] Algvere, P.V., Gouras, P. and Dafgard Kopp, E. (1999) Long-term outcome of RPE allografts in non-immunosuppressed patients with AMD. European Journal of Ophthalmology, 9, 217-230.

[34] Tomita, M., Adachi, Y., Yamada, H., Takahashi, K., Kiuchi, K., Oyaizu, H., Ikebukuro, K., Kaneda, H., Matsumura, M. and Ikehara, S. (2002) Bone marrow-derived stem cells can differentiate into retinal cells in injured rat retina. Stem Cells, 20, 279-283. doi:10.1634/stemcells.20-4-279

[35] Tomita, M., Yamada, H., Adachi, Y., Cui, Y., Yamada, E., Higuchi, A., Minamino, K., Suzuki, Y., Matsumura, M. and kehara, S. (2004) Choroidal neovascularization is provided by bone marrow cells. Stem Cells, 22, 21-26. doi:10.1634/stemcells.22-1-21

[36] Inoue, Y., Iriyama, A., Ueno, S., Takahashi, H., Kondo, M., Tamaki, Y., Araie, M. and Yanagi, Y. (2007) Subretinal transplantation of bone marrow mesenchymal stem cells delays retinal degeneration in the RCS rat model of retinal degeneration. Experimental Eye Research, 85, 234241. doi:10.1016/j.exer.2007.04.007

[37] Lund, R.D., Wang, S., Lu, B., Girman, S., Holmes, T., Sauvé, Y., Messina, D.J., Harris, I.R., Kihm, A.J., Harmon, A.M., Chin, F.Y., Gosiewska, A. and Mistry, S.K. (2007) Cells isolated from umbilical cord tissue rescue photore- ceptors and visual functions in a rodent model of retinal disease. Stem Cells, 25, 602-611.

doi:10.1634/stemcells.2006-0308

[38] Canola, K., Angenieux, B., Tekaya, M., Quiambao, A., Naash, M.I., Munier, F.L,, Schorderet, D.F. and Arsenijevic, Y. (2007) Retinal stem cells transplanted into models of late stages of retinitis pigmentosa preferentially adopt a glial or a retinal ganglion cell fate. Investigative Ophthalmology and Visual Science, 48, 446-454. doi:10.1167/iovs.06-0190

[39] MacLaren, R.E., Pearson, R.A., MacNeil, A., Douglas, R.H., Salt, T.E., Akimoto, M., Swaroop, A., Sowden, J.C. and Ali, R.R. (2006) Retinal repair by transplantation of photoreceptor precursors. Nature, 444, 203-207.

[40] Coles, B.L., Angénieux, B., Inoue, T., Del Rio-Tsonis, K., Spence, J.R. McInnes, R.R., Arsenijevic, Y. and van der Kooy, D. (2004) Facile isolation and the characterization of human retinal stem cells. Proceedings of the National Academic of Science of the USA, 101, 15772-15777. doi:10.1073/pnas.0401596101

[41] Yang, J., Klassen, H., Pries, M., Wang, W. and Nissen, M.H. (2006) Aqueous humor enhances the proliferation of rat retinal precursor cells in culture, and this effect is partially reproduced by ascorbic acid. Stem Cells, 24, 27662775. doi:10.1634/stemcells.2006-0103

[42] Merhi-Soussi, F., Angénieux, B., Canola, K., Kostic, C., Tekaya, M., Hornfeld, D. and Arsenijevic Y. (2006) High yield of cells committed to the photoreceptor fate from expanded mouse retinal stem cells. Stem Cells, 24, 20602070. doi:10.1634/stemcells.2005-0311

[43] Mori, T., Kiyono, T., Imabayashi, H., Takeda, Y., Tsuchiya, K., Miyoshi, S,, Makino, H., Matsumoto, K., Saito, H., Ogawa, S., Sakamoto, M., Hata, J. and Umezawa, A. (2005) Combination of hTERT and bmi-1, E6, or E7 induces prolongation of the life span of bone marrow stromal cells from an elderly donor without affecting their neurogenic potential. Molecular and Cellular Biology, 25, 5183-5195. doi:10.1128/MCB.25.12.5183-5195.2005

[44] Ahmad, I., Tang, L. and Pham, H. (2000) Identification of neural progenitors in the adult mammalian eye. Biochemical and Biophysical Research Communications, 270, $517-$ 521. doi:10.1006/bbrc.2000.2473

[45] Mayer, E.J., Hughes, E.H., Carter, D.A. and Dick, A.D. (2003) Nestin positive cells in adult human retina and in epiretinal membranes. British Journal of Ophthalmology, 87, 1154-1158. doi:10.1136/bjo.87.9.1154

[46] Mukhopadhyay, M., Shtrom, S., Rodriguez-Esteban, C., Chen, L., Tsukui, T., Gomer, L., Dorward, D.W., Glinka, A., Grinberg, A., Huang, S.P., Niehrs, C., Izpisúa Belmonte, J.C. and Westphal, H. (2001) Dickkopf1 is required for embryonic head induction and limb morphogenesis in the mouse. Developmental Cell, 1, 423-434. doi:10.1016/S1534-5807(01)00041-7

[47] Mukhopadhyay, M., Gorivodsky, M., Shtrom, S., Grinberg, A., Niehrs, C., Morasso, M.I. and Westphal, H. (2006) Dkk2 plays an essential role in the corneal fate of the ocular surface epithelium. Development, 133, 21492154. doi:10.1242/dev.02381

[48] Glinka, A., Wu, W., Delius, H., Monaghan, A.P., Blumen- 
stock, C. and Niehrs, C. (1998) Dickkopf-1 is a member of a new family of secreted proteins and functions in head induction. Nature, 391, 357-362.

[49] Pera, E.M., Wessely, O., Li, S.Y. and De Robertis, E, M. (2001) Neural and head induction by insulin-like growth factor signals. Developmental Cell, 1, 655-665. doi:10.1016/S1534-5807(01)00069-7

[50] Lim, D.A., Tramontin, A.D., Trevejo, J.M., Herrera, D.G., García-Verdugo, J.M. and Alvarez-Buylla, A. (2000) Noggin antagonizes BMP signaling to create a niche for adult neurogenesis. Neuron, 28, 713-726. doi:10.1016/S0896-6273(00)00148-3

[51] Hollis, E.R. II., Lu, P., Blesch, A. and Tuszynski, M.H. (2009) IGF-I gene delivery promotes corticospinal neuronal survival but not regeneration after adult CNS injury. Experimental Neurology, 215, 53-59. doi:10.1016/j.expneurol.2008.09.014

[52] Xu. S., Sunderland, M.E., Coles, BL, Kam, A., Holowacz, T., Ashery-Padan, R., Marquardt, T., McInnes, R.R, and van der Kooy, D. (2007) The proliferation and expansion of retinal stem cells require functional pax6. Development Biology, 304, 713-721. doi:10.1016/j.ydbio.2007.01.021

[53] Zaghloul, N.A. and Moody, S.A. (2007) Alterations of $r \times 1$ and pax6 expression levels at neural plate stages differentially affect the production of retinal cell types and maintenance of retinal stem cell qualities. Developmental Biology, 306, 222-240. doi:10.1016/j.ydbio.2007.03.017

[54] Gu, P., Yang, J., Wang, J., Young, M.J. and Klassen, H. (2009) Sequential changes in the gene expression profile of murine retinal progenitor cells during the induction of differentiation. Molecular Vision, 15, 2111-2122.

[55] Schmitt, S., Aftab, U., Jiang, C., Redenti, S., Klassen, H., Miljan, E., Sinden, J. and Young, M. (2009) Molecular characterization of human retinal progenitor cells. Investigative Ophthalmology and Visual Science, 50, 5901-
5908. doi:10.1167/iovs.08-3067

[56] Klassen, H., Kiilgaard, J.F., Zahir, T., Ziaeian, B., Kirov, I., Scherfig, E., Warfvinge, K. and Young, M.J. (2007) Progenitor cells from the porcine neural retina express photoreceptor markers after transplantation to the subretinal space of allorecipients. Stem Cells, 25, 1222-1230. doi:10.1634/stemcells.2006-0541

[57] Klassen, H., Sakaguchi, S., Young, M. (2004) Stem cells and retinal repair. Progress in Retinal and Eye Research, 23, 149-181. doi:10.1016/j.preteyeres.2004.01.002

[58] Qiu, F., Jiang, H., Xiang, M. (2008) A comprehensive negative regulatory program controlled by Brn3b to ensure ganglion cell specification from multipotential retinal precursors. Journal of Neuroscience, 28, 3392-3403. doi:10.1523/JNEUROSCI.0043-08.2008

[59] Liu. W., Mo, Z. and Xiang M. (2001) The Ath5 proneural genes function upstream of Brn3 POU domain transcripttion factor genes to promote retinal ganglion cell development. Proceeding of National Academic Science of the USA. 98, 1649-1654. doi:10.1073/pnas.98.4.1649

[60] Ma, W., Yan, R.T., Xie, W. and Wang, S.Z. (2004) A role of ath5 in inducing neuroD and the photoreceptor pathway. Journal of Neuroscience, 24, 7150-7158. doi:10.1523/JNEUROSCI.2266-04.2004

[61] Tondreau, T., Lagneaux, L., Dejeneffe, M., Massy, M., Mortier, C., Delforge, A. and Bron, D. (2004) Bone marrow-derived mesenchymal stem cells already express specific neural proteins before any differentiation. Differentiation, 72, 319-326. doi:10.1111/j.1432-0436.2004.07207003.x

[62] Mareschi, K., Novara, M., Rustichelli, D., Ferrero, I., Guido, D., Carbone, E., Medico, E., Madon, E., Vercelli, A. and Fagioli, F. (2006) Neural differentiation of human mesenchymal stem cells: Evidence of neuronal markers and eag $\mathrm{K}^{+}$channel types. Experimental Hematology, 34, 1563-1575. doi:10.1016/j.exphem.2006.06.020 